\title{
DE VIAGENS E VIAJANTES: CAMÕES, GARRETT E SARAMAGO
}

Teresa Cristina Cerdeira da Silva Universidade Federal do Rio de Janeiro

Une oeuvre est éternelle non pas parce qu'elle impose un sens unique à des hommes différents, mais parce qu'elle suggère des sens différents à un homme unique, qui parle toujours la même langue symbolique à travers des temps multiples: l'oeuvre propose, l'homme dispose.

Roland Barthes

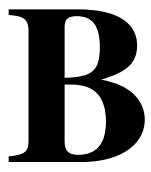

arthes um dia afirmou: - "Le livre est un monde" -, ilustrando as possibilidades incontornáveis das suas leituras. Na tradição portuguesa, falar de viagens é redundância a que se não pode fugir. Ou talvez sim, não por escapar à fatalidade da viagem, mas à fatalidade da própria redundância. Escrever é sempre uma fratura do mundo e do livro. Não só a história, mas também os livros não se repetem a não ser como farsa. Porque ao repetir citamos e recortamos, deslocamos de um universo de referências e exercitamos um a mais que é do domínio da diferença. A diferença hoje aqui tem um nome - Almeida Garrett e depois dele um outro nome, José Saramago, ambos autores que souberam recortar das viagens celebráveis d'Os Lusíadas o material que funda as Viagens na minha terra e a Viagem a Portugal.

A história permanece como discurso. Camões o sabia bem. Sabia que "cantando" espalharia por toda parte a história da navegação portuguesa. Sabia mesmo ou adivinhava - talvez um pouco mais - que, em tempos em que o país escrevia já uma história trágico-marítima, a sua épica tinha aquela função a que metaforicamente Eduardo Lourenço chamou de "último canto do cisne", canto 
de força de uma nação às vésperas do apagamento lento em que se lançaria nos séculos por vir.

O que talvez não soubesse o poeta, ou o que talvez não lhe coubesse imaginar - tão grande parecia nesse ponto o destino do seu livro - era a rota transgressora que o seu poema empreenderia no interior da cultura portuguesa. Rota transgressora, não somente porque fazia coincidir na épica - gênero alto, entre todos respeitado desde a antigüidade - a presença do lírico, a presença de um eu que o cânone tradicional conscientemente obliterava e, por aí, introduzir insidiosamente as falas do amor e do discurso crítico. Disso ele estava consciente, porque era consciente o exercício da sua escrita. O nível da transgressão que não adivinhara para Os Lusíadas era aquele que advinha de uma inversão diabólica que a ficção impunha à História. Nascida a escrita poética de uma necessária convivência com os feitos heróicos da nacionalidade e da maturação dessa tradição na alma do poeta, tornar-se-ia ela própria, para um povo ávido de manter presente a glória que se esfacelara, não mais a ficção sonora e belicosa da História, mas a fonte de onde a própria História se recuperaria. Se a História gerara a ficção de modo a fazêla "símbolo" de um tempo, por um processo já agora não mais "simbólico" - no sentido grego de symbolos (lançar junto, jogar o mesmo) -, mas "diabólico" - de diabolos ("lançar contra ou através") ${ }^{1}$ - do discurso, a ficção se tornava ela própria História, a partir da qual se fundaria o imaginário da pátria. Genialidade da

${ }^{1}$ Necessário referir aqui a comunicação de Edson Rosa da Silva: "Michel Tournier: versão e inversão dos mitos", apresentado na XII Semana de Estudos Clássicos, na UFRJ, em setembro de 1991, do qual citamos a seguinte passagem: "A criação do neologismo "diabole" por oposição a "symbole" permite-nos ler o "diabolo" como uma desconstrução do "símbolo". Para revitalizar, é preciso, segundo Michel Tournier inverter, diabolizar, não mais aceitar passivamente os símbolos que nos impõe nossa cultura, pensar com ela, lançar-nos (syn-ballein), mas pensar contra ela, penetrando-a, lançando-nos através (dia-ballein), para atravessá-la e ver o outro lado. Pois os símbolos aceitos sem contestação fecham o horizonte." 
escrita? Oportunidade do texto? Difícil é encontrar uma razão, porque possivelmente haverá muitas, quer ligadas intrinsicamente ao poema grandioso, quer à qualidade de sua recepção ao longo dos séculos. A própria necessidade de evocá-lo aqui, para saltar depois sobre ele - ou, quem sabe, talvez não - para chegar a outras "viagens" que vão de Garrett a Saramago, é mais que uma prova da sua permanência inalterável, é antes a consciência da passagem obrigatória que por ele se faz, mesmo que para desmontar a aura sagrada que a cegueira das leituras lhe impôs para evitar que fosse lido nas contradições que já então queria apontar. Corroendo com a viagem dolorosa do poeta a viagem grandiosa do Gama, Camões insinuava, no interior do seu poema, que a história portuguesa estava fadada menos às memórias gloriosas do que à história trágicomarítima. Se o tempo não era chegado de destecer a épica da navegação, ao menos incluía ele o tom dissonante que faria dela, também neste sentido, uma experiência decididamente moderna.

De certo modo o percurso das viagens portuguesas não parece ainda hoje ter chegado ao fim. Das viagens gloriosas do tempo dos Descobrimentos, às viagens fantasmáticas nos séculos que se seguiram, em que só de passado se tecia a glória, às viagens da emigração pela perseguição religiosa ou política, ou pela falência material do país, à viagem dos retornados dos anos 70 ou à viagem para a Europa dos anos 80, Portugal continua a ser "um país em viagem", como lhe chamou José Cardoso Pires, em artigo do Jornal de Letras de 1980. O certo é que frases emblemáticas pontuam esse destino ou essa fatalidade: o verso camoniano, por um lado, que define a pátria como um cais de partida - "aqui onde a terra se acaba e o mar começa"; por outro, a entrada emblemática de um grande romance - "aqui o mar acaba e a terra principia" ou, em sua variante à guisa de desfecho: "aqui onde o mar se acabou e a terra espera" - que desloca o movimento de entrada e saída, de modo a ver essa mesma pátria como o espaço a conquistar, a terra onde se tem que

${ }^{2}$ SARAMAGO, 1984. 
aprender a viajar, o "exíguo quintal" que é preciso conhecer, metáfora que no texto de Eduardo Lourenço ${ }^{3}$ retoma em eco aquele outro quintal que só podemos conceber povoado de laranjeiras que crescem na horta de um também outro Xavier de Maistre nascido por acaso em terras mais a ocidente e que se recusa a suportar os limites estreitos de uma viagem em volta do seu quarto. A questão está colocada: se a falência da imagem secular do país como cais de partida parece ser articulada quando o império se desfaz nos anos 70, a consciência da necessidade desse olhar para dentro de casa é um projeto que Garrett já anuncia com perspicácia nas suas Viagens na minha terra. Com elas inaugura ele uma proposta de releitura de Portugal no avesso das viagens portuguesas, ou, se quisermos, com sinal oposto ao da apologética do mar como símbolo da glória nacional. Garrett faz, sim, um livro de "viagens", para situá-lo no contexto lusíada de um país de marinheiros. Mas essas são, agora, viagens na (sua) terra portuguesa, aquela que fica aquém-mar, desconhecida e abandonada pelos olhos de uma "política de transporte" que aniquilou a fixação positiva do homem à terra. Para assinalar este sinal contrário a um movimento secular, parte de Lisboa e do Terreiro do Paço onde desembarcavam outrora as riquezas do Império; e parte também de barco, porque marinheiras eram todas as viagens da tradição lusíada. Mas é aí, onde a similitude se implantaria, que a perversão se inaugura. O barco não repete as naus, porque não é glorioso e dele não se espera, ao menos, - tão lento vai - que seja o primeiro numa "regata de vapores". ${ }^{4}$ Logo se descobre, entretanto, que a sua falência não é tecnológica: ela se justifica tão somente pela direção do caminho empreendido. Esse

3 "Chegou a hora de fugir para dentro de casa, de nos barricarmos dentro dela, de construir com constância o país habitável de todos, sem esperar de um eterno lá fora ou lá-longe a solução que como no apólogo célebre está enterrada no nosso exíguo quintal. Psicanálise mítica do destino português". LOURENÇO, 1978, p. 51.

${ }^{4}$ GARRETT, 1946, p.44. 
barco não desce o Tejo, rumo "ao largo oceano"; ele caminha, ao contrário, "Tejo-arriba", para ir ao encontro do "quintal português", "onde a laranjeira cresce na horta e o mato é de murta". ${ }^{5} \mathrm{O}$ barco vai conhecer o Portugal interior, vai acompanhar o narrador na parte inicial de sua viagem a Santarém, viagem pequena, certamente, se pensarmos em geografia, viagem sem glória, sem adasmatores nem fogos de santelmo. E, no entanto, viagem importante, para dentro de um Portugal a re-conhecer, para dentro da cultura, para dentro das tradições, para dentro da História; viagem ainda de explorador sagaz que, subvertendo o traçado primeiro, investe em viagens paradigmáticas múltiplas a se inscreverem na sintaxe do mero deslocamento espacial que a viagem física prometia.

Claro está que Lisboa ocupa espaço estratégico na leitura que faz Garrett do destino português. É de lá que parte, é a ela que retorna, e a imagem que fica da cidade, nessa navegação nada épica, feita pela contramão da ideologia, é a de uma cidade contemplada pelo vagar de um barco a subir o Tejo, na contra-corrente do rio e na contra-corrente da História. Não mais "a ocidental praia lusitana" de onde os heróis-navegadores partiram para conhecer "os mares nunca de outrem navegados", mas justamente "este majestoso e pitoresco anfiteatro de Lisboa oriental", a que guarda mais presente as tradições da "nossa velha e boa Lisboa das crônicas"; uma Lisboa onde tudo é menos "prosaico e burguês, chato, vulgar e sensabor", a Lisboa da Madre de Deus e das hortas de Chelas.

A um lado a imensa majestade do Tejo em sua maior extensão e poder, que ali mais parece um pequeno mar mediterrâneo; do outro a frescura das hortas e a sombra das árvores, palácios, mosteiros, sítios consagrados a recordações grandes e queridas. Que outra saída tem Lisboa que se compare em beleza com esta? Tirado Belém, nenhuma. E, ainda assim, Belém é mais árido. ${ }^{6}$

${ }^{5}$ GARRETT, 1946, p. 3.

${ }^{6}$ GARRETT, 1946, p. 6. 
A ousadia do narrador é imensa: substitui a grandeza épica pela paz bucólica, a praia ocidental pela Lisboa oriental, a Lisboa burguesa pela Lisboa popular, o "grande oceano por achar" pelo "pequeno mar mediterrâneo" e a epopéia do mar pela tradição da terra nessa porta de saída da cidade que tem mais beleza nas suas hortas e nas suas árvores que a aridez monumental de Belém. Afinal não era Belém uma metáfora do projeto expansionista que tornara definitivamente árida a terra portuguesa?

Garrett impõe um novo olhar para a história que começa por uma perversão do modelo expansionista onde Lisboa era o centro dos olhares. Ensina a olhar a cidade por uma outra perspectiva - que é física, literal e também evidentemente metafórica. Ensina um outro percurso para a viagem dos portugueses aquela que lhe permitirá viajar "com muito prazer e com muita utilidade e proveito na nossa / sua boa terra”. Pontual este senhor Almeida Garrett! Pontual quando se firma numa política do concreto, como bem viu Helder Macedo, ${ }^{7}$ no conhecido ensaio "As Viagens na minha terra ou A menina dos rouxinóis", pontual quando acredita no povo como aquele que poderia construir o "país habitável de todos"; pontual quando exige estradas de pedra e recusa a megalomania industrial de um país pobremente agrário a querer enveredar pelo modelo inglês das estradas de ferro; pontual quando pretende acordar o país da falsa imagem gloriosa que criara para si mesmo, ao assinalar irônica e sutilmente o fim da épica dos mares em nome de uma terra por reconhecer. De certa maneira o primeiro requiem para Os Lusíadas se tecia nessa nova proposta onde o "prazer" não estava mais na ficção de uma glória passada, mas na certeza do "proveito" e da "utilidade" dos seus projetos viáveis. A viagem proposta pela terra não é de modo algum ufanista. Nem se faz, como seria de esperar de uma narrativa de viagem romântica, pelos recantos exóticos ou especialmente "turísticos" - com a desculpa do adjetivo anacrônico - de Portugal. De certo modo a narrativa de Garrett está

${ }^{7}$ MACEDO, 1979, p. 15-24. 
mais para as viagens iluministas do século XVIII que propriamente para o modelo do exotismo do século XIX, em que o caráter descritivo parece ganhar espaço sobre a proposta de aprendizado. Certamente, no início do romance, o narrador das Viagens não é o ingênuo Candide, mas não se pode negar que a estratégia da inserção da novela da Casa do Vale no tecido do romance funciona como uma metáfora - e retomo aqui leituras críticas anteriores que se tornaram incontornáveis em se tratando deste romance de Garrett ${ }^{8}$ - uma metáfora, repito, que ilustra para o leitor, à maneira de um conto filosófico, um certo modo nada maniqueísta de entender a marcha da sociedade: Quixotes e Sanchos não excludentes que se vislumbram lado a lado na síntese de um "Errámos ambos". Aprender a viajar na terra, na (sua) terra, é a forma que o narrador encontra para fazer desmontar a máscara do falso conhecimento nacional e de promover o discurso de apreensão de uma possível identidade portuguesa.

A linhagem do olhar crítico garrettiano sobre o diálogo entre a terra e o mar na cultura portuguesa chega ao fim do século XX, não sem antes passar evidentemente pelo peixe podre de um Tejo em cujo cais se amarram botes, em cujas águas voga um encouraçado inglês, e pelos filhos de varinas varonis que depois naufragam nas tormentas: Cesário invocado por esse sentimento dum outro olhar que se lança a partir de uma certa ocidental praia lusitana. Preparavam eles - Garrett e Cesário - a viagem para dentro de O ano da morte de Ricardo Reis e a recusa da viagem para a Europa de $A$ Jangada de Pedra que em José Saramago, para além do fato concreto da crítica à adesão de Portugal à CEE (ou hoje à UE), significa ir buscar na terra - ampliada agora para as dimensões da península ibérica - as fontes de reverdecimento e fertilidade da vara seca de negrilho. Viajar na própria terra tinha sido, entretanto, antes dessas construções metafóricas, um projeto concreto de José Saramago no livro de clara herança garrettiana que se chama Viagem

${ }^{8}$ MONTEIRO, 1976 e MACEDO, 1979. 
a Portugal. Dedicado a Garrett, "mestre de viajantes", esse texto se propõe fundamentalmente a "reparar" na terra e a incitar a outras viagens, de que não se afasta aquela que pode ser feita no próprio texto-terra em que outros viajarão, sem serem obrigados a um roteiro imposto, tendo o direito de escolher os fios da meada que lhe aprouverem, porque este é também um livro em que se pode entrar por muitas portas, que deixa o viajante-leitor suficientemente livre até mesmo para "enganar-se na estrada e voltar atrás". Lição garretiana aprendida, esse texto é um falso livro de turismo, como o outro era um falso diário de viagem. Dialogando com a célebre proposta "de quanto vir e ouvir, de quanto pensar e sentir se há de fazer crônica", encontramos já no prólogo a sugestão: "registe por sua vez o que viu e sentiu, o que disse e ouviu dizer". Também sabe o viajante que uma viagem, mesmo segura, precisa de boas mãos que o guiem, Tágides generosas para que chegue a bom termo o seu projeto. Só que a invocação é feita aos peixes a quem saúda e pede a bênção, possivelmente porque têm eles a sabedoria da comunhão e o descaso pela divisão artificiosa das fronteiras.

"Vinde cá, peixes, vós da margem direita que estais no Douro, e vós da margem esquerda que estais no rio Duero, vinde cá e dizeis que língua é a que falais quando aí em baixo cruzais as aquáticas alfândegas (...) Aqui estou eu, olhando para vós do alto desta barragem, e vós para mim, peixes que viveis nessas confundidas águas, que tão depressa estão duma banda como da outra, em grande irmandade de peixes que uns aos outros só se comem por necessidades de fome e não por enfados de pátria. (...) e desejai-me boa viagem, adeus, adeus".

Se este não é um livro de turismo, é que não quer impor roteiros, já o sabemos, e que mais que descritivo da paisagem, é historiador da cultura. Falará por isso, como acima inferimos, da tensão secular dos vizinhos Portugal e Espanha, falará das estórias populares, alterará o conceito de ver muito em prol do "estar mais", relembrará os textos da tradição - Camilo e o seu Calixto Elói,

9 SARAMAGO, 1985, p.7. 
Teixeira de Pascoaes, Aquilino Ribeiro e Torga, e tantas outras memórias literárias em que se inclui o delicioso sabor garrettiano de olhar para uma "janela iluminada, certamente, oh certamente, o quarto da Bela Adormecida"; saboreará os nomes e as palavras de tal modo que, dirá, "nem precisa de outro alimento"; fará comentários estéticos e críticas ao descaso das tradições e ao descuido das obras de arte. Mas também, à maneira do seu "mestre de viajantes", fará a história do eu - descentrado, é bem verdade, numa virtual terceira pessoa: "o viajante" - e refletirá, como ele, sobre a forma de narrar:

O viajante tem o dever de medir as palavras. Não lhe fica bem desmandar-se em adjectivos, que são a peste do estilo, muito mais quando substantivo se quer como neste caso. Mas a Igreja de Nossa Senhora da Orada, pequena construção românica decentemente restaurada, é tal obra-prima de escultura que as palavras são fatalmente demais porque são desgraçadamente de menos. ${ }^{10}$

Se este não é um livro de turismo - embora em sua edição com imagens certamente aparente sê-lo - é que o gênero informativo, sintético, objetivo, auxiliar do olhar apressado, aqui se vê traído pelo espaço concedido a variadíssimas formas de discurso especulativo ou mesmo hipotético, que contradizem a técnica da economia do catálogo de informações. "Se houvesse fantasmas em Portugal este sítio seria perfeito para assustar os viajantes" - eis uma fórmula nada convencional de narrar a chegada a uma aldeia do interior, quando a noite é já entrada. E conclui: "As povoações são como as pessoas, aproximamo-nos delas devagar, paulatinamente, não esta invasão súbita, a coberto da escuridão, como se fôssemos salteadores mascarados". A hora da chegada gera um discurso ético, reflexivo; o ponto de partida condicional faz, das descrições, considerações hipotéticas, onde se multiplicam as formas do discurso modalizante: "o sítio seria bom", "talvez um estridor de dentes", "porém, quem sabe, talvez que às horas do dia”...

${ }^{10}$ SARAMAGO, 1985, p. 53-54. 
Se este não é um livro de turismo, é porque, ao lado das informações históricas, com suas certezas e com seu ar de grande verdade, caminham as aventuras imaginárias que constróem outro tipo de maravilhas em que se insinuam a sedução e a paixão: "o viajante está prestes a adormecer, quem sabe se nesta cama de dossel dormiu sua majestade o rei ou, talvez, preferível, sua alteza a princesa".

Se este não é um livro de turismo, é porque viajar pela sua terra é sobretudo uma forma de reconhecimento, que não tem nada a ver com o olhar estrangeiro, ao contrário, é um olhar de dentro e para dentro das tradições e da cultura. Por isso, mesmo as legendas das fotografias que, destacadas em itálico, poderiam insinuar um outro tipo de discurso - o esperado dêitico e informativo -, continuam, na verdade, o tom reflexivo da escrita. Uma imagem onde há apenas árvores outonais gera, por exemplo, uma consideração metafísica sobre a inexorabilidade do tempo, diante do contraste entre a eterna circularidade natural e o desgaste das obras do homem. É a outra forma possível de falar sobre a Igreja de Azinhoso, por eleição da imagem do comparado (natureza) e silenciamento visual do comparante (pedra).

Caem as folhas do Outono, não tarda que a Primavera as renove. As pedras resistem doutra maneira: sobre a porta da igreja de Azinhoso já passaram oitocentos anos: mas acabando-se-lhe o tempo, não haverá Primavera... ${ }^{11}$

Enfim, porque é este um roteiro que aqui não cabe por inteiro, restaria dizer que essa viagem começa, não por sair de Portugal, mas por entrar em Portugal, faz-se da fronteira para dentro, em plenas terra do norte, e elege como ponto final ou da chegada da viagem, "que não é nunca definitiva", diz o narrador ou o viajante, o caminho da Finisterra do Sul, a ponta de Sagres, de onde antes se partia e onde ele agora finda a sua viagem de conhecimento. E dirá: "o

${ }^{11}$ SARAMAGO, 1985 p.11. 
viajante tem de voltar para casa. (...) Este é o país do regresso. A viagem acabou".

E agora nos perguntamos: Que viagem afinal acabou? Esta concreta do viajante ou aquela outra que fazia partir de Sagres, espaço do saber de navegar? O que esta viagem mais uma vez ensina é a lição de Garrett, é a navegação Tejo-arriba, é o fim da epopéia do mar. Porque viajar é destino português e tal como dirá o viajante amante da sua terra:

A viagem não acaba nunca. Só os viajantes acabam. E mesmo estes poderão prolongar-se em memória, em lembrança, em narrativa. (...) O fim de uma viagem é sempre o começo doutra. É preciso ver o que não foi visto, ver outra vez o que se viu já, ver na Primavera o que se vira no Verão, ver de dia o que se viu de noite, com Sol onde primeiramente a chuva caíra, ver a seara verde, o fruto maduro, a pedra que mudou de lugar, a sombra que aqui não estava. É preciso voltar aos passos que foram dados, para os repetir, e para traçar caminhos novos ao lado deles. É preciso recomeçar a viagem. Sempre. ${ }^{12}$

A fonte dessa proposta de leitura, que chamou ao mesmo terreno de reflexão um Camões, um Garrett e um Saramago, não está longe do projeto que acabamos de conhecer: o de que o fim de uma viagem textual é sempre o recomeço de outra e de que, por isso mesmo, "O viajante volta já".

${ }^{12}$ SARAMAGO, 1985, p.233. 


\section{Referências Bibliográficas}

BARTHES, Roland. Critique et vérité. Paris: Éditions du Sevil, 1964. GARRETT, Almeida. Viagens na minha terra. Porto: Livraria Tavares Martins, 1946.

LOURENÇO, Eduardo. Labirinto da saudade. Lisboa: Dom Quixote, 1978.

MACEDO, Helder. Viagens na minha terra ou a menina dos rouxinóis. Colóquio Letras, Lisboa, n. 51, p. 15-24, set. 1979.

MONTEIRO, Ofélia de Paiva. Algumas reflexões sobre a novelística de Garrett. Colóquio Letras, n. 30, p. 13-29, mar. 1976.

SARAMAGO, José. O ano da morte de Ricardo Reis. Lisboa: Caminho, 1984.

SARAMAGO, José. Viagem a Portugal. Lisboa: Caminho, 1985. 


\section{Resumo}

Leitura do projeto estético, ético e ideológico da tradição de viagens portuguesas a partir de Viagens na minha terra, de Almeida Garrett, e Viagem a Portugal, de José Saramago, textos que se constróem no avesso da tradição épica camoniana. Separados por mais de um século, esses textos se respondem, não apenas por uma afinidade temática e por uma relação de débito confessado do segundo em relação ao primeiro, mas sobretudo como narrativas de viagem no seio de uma tradicional cultura viageira, e como projeto de dar visibilidade a um país através de estratégias que, se são evidentemente diversas pela distância temporal que separa as duas produções - não deixam de orientar-se por uma ética que resgata no povo a fonte benfazeja da tradição e da história.

\section{Résumé}

Lecture du projet esthétique, éthique et idéologique de la tradition des voyages portugais à partir de Viagens na minha terra, d' Almeida Garrett, et de Viagem a Portugal, de José Saramago, textes qui se créent à l'envers du mouvement traditionnel de l'épopée camonienne. Eloignés de plus d'un siècle, ces deux textes se répondent, non seulement par leurs affinités thématiques et par une dette confessée du second par rapport au premier, mais surtout par le fait de constituer des récits de voyage, dans l'ensemble d'une traditionnelle culture de voyageurs, et d'avoir tous les deux le but de rendre visible la terre portugaise à travers des stratégies qui, sûrement diverses - par la distance temporelle qui les sépare -, retrouvent leur fondement éthique dans l'image du peuple, source bienfaisante de la tradition et de l'histoire. 